\title{
Chronic oxytocin-driven alternative splicing of Crfr2a induces anxiety
}

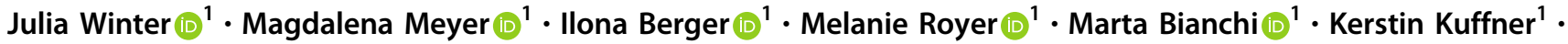 \\ Sebastian Peters ${ }^{2}$ - Simone Stang ${ }^{1}$ - Dominik Langgartner ${ }^{3}$ - Finn Hartmann $\mathbb{D}^{1}$ - Anna K. Schmidtner ${ }^{1}$. \\ Stefan O. Reber $\mathbb{1}^{3}$. Oliver J. Bosch $\mathbb{1}^{1} \cdot$ Anna Bludau $\mathbb{1}^{1} \cdot$ David A. Slattery $\mathbb{D}^{4}$ - Erwin H. van den Burg $\mathbb{1}^{5}$. \\ Benjamin Jurek $\mathbb{D}^{1,6} \cdot$ Inga D. Neumann $\mathbb{B}^{1}$
}

Received: 27 November 2020 / Revised: 25 March 2021 / Accepted: 20 April 2021

(c) The Author(s) 2021. This article is published with open access

\begin{abstract}
The neuropeptide oxytocin (OXT) has generated considerable interest as potential treatment for psychiatric disorders, including anxiety and autism spectrum disorders. However, the behavioral and molecular consequences associated with chronic OXT treatment and chronic receptor (OXTR) activation have scarcely been studied, despite the potential therapeutic long-term use of intranasal OXT. Here, we reveal that chronic OXT treatment over two weeks increased anxiety-like behavior in rats, with higher sensitivity in females, contrasting the well-known anxiolytic effect of acute OXT. The increase in anxiety was transient and waned 5 days after the infusion has ended. The behavioral effects of chronic OXT were paralleled by activation of an intracellular signaling pathway, which ultimately led to alternative splicing of hypothalamic corticotropin-releasing factor receptor $2 \alpha(\operatorname{Cr} f r 2 \alpha)$, an important modulator of anxiety. In detail, chronic OXT shifted the splicing ratio from the anxiolytic membrane-bound (mCRFR2 $\alpha$ ) form of CRFR2 $\alpha$ towards the soluble CRFR2 $\alpha$ (sCRFR2 $\alpha$ ) form. Experimental induction of alternative splicing mimicked the anxiogenic effects of chronic OXT, while sCRFR $2 \alpha$-knock down reduced anxiety-related behavior of male rats. Furthermore, chronic OXT treatment triggered the release of sCRFR $2 \alpha$ into the cerebrospinal fluid with sCRFR $2 \alpha$ levels positively correlating with anxiety-like behavior. In summary, we revealed that the shifted splicing ratio towards expression of the anxiogenic sCRFR $2 \alpha$ underlies the adverse effects of chronic OXT treatment on anxiety.
\end{abstract}

These authors contributed equally: Erwin H. van den Burg, Benjamin Jurek, Inga D. Neumann

Supplementary information The online version contains Supplementary Material available at https://doi.org/10.1038/s41380021-01141-x.

Inga D. Neumann

inga.neumann@ur.de

1 Department of Behavioural and Molecular Neurobiology, Regensburg Center of Neuroscience, University of Regensburg, Regensburg, Germany

2 Department of Neurology, University Hospital Regensburg, Regensburg, Germany

3 Laboratory for Molecular Psychosomatics, Department of Psychosomatic Medicine and Psychotherapy, University of Ulm, Ulm, Germany

\section{Introduction}

Neuropeptides and their receptors are established modulators of neuronal activity, shaping multiple behavioral and physiological responses to environmental stimuli. Neuropeptide signaling is, therefore, an important target for the development of pharmacological treatments of psychopathologies, such as autism-spectrum, anxiety and substance-use disorders,

4 Laboratory of Translational Psychiatry, Department of Psychiatry, Psychosomatic Medicine and Psychotherapy, University of Frankfurt, Frankfurt am Main, Germany

5 Center for Psychiatric Neurosciences, University Hospital Lausanne, Lausanne, Switzerland

6 Institute for Molecular and Cellular Anatomy, University of Regensburg, Regensburg, Germany 
or schizophrenia, among others $[1,2]$ associated with social and emotional dysfunctions. In this context, the neuropeptide oxytocin (OXT) has received considerable attention over the last decades due to its profound prosocial, fear-reducing and anxiolytic effects demonstrated both in human and animal studies [3]. Studies in rodents have shown that the multiple behavioral effects of acute OXT can be induced within the paraventricular nucleus of the hypothalamus (PVN) $[4,5]$, central amygdala [6-8], lateral septum [9, 10], and cortical [11] and brainstem [12] regions.

OXT is synthesized in the PVN and supraoptic nuclei of the hypothalamus, where it is released somato-dendritically in response to stressful and fear-enhancing stimuli [3, 13, 14]. Such locally-released OXT, e.g., within the PVN, as well as acute local OXT infusions, exert robust anxiolytic effects in rats, shown in several relevant behavioral tests $[4,5]$. Within the PVN, OXT also acts as neuromodulator of social behaviors $[15,16]$ and physiological functions including the regulation of the hypothalamicpituitary-adrenal axis and stress-induced secretion of adrenocorticotropin (ACTH) and corticosterone [17, 18].

On a molecular level, the $G$ protein-coupled OXT receptor (OXTR) is linked to multiple intraneuronal signaling cascades [3, 19]. In brief, the $\mathrm{G}$ protein $\alpha_{q}$ subunit is at the basis of activation of protein kinase C (PKC) [20], whereas the $\beta / \gamma$ subunit activates $\mathrm{Ca}^{2+}$-influx through transient receptor potential vanilloid type 2 (TRPV2) and other $\mathrm{Ca}^{2+}$ channels $[3,21]$. This is followed by the recruitment of mitogen-activated protein kinase (MAPK) kinase (MEK1/2) signaling [21] and protein synthesis [20]. Both MEK1/2 signaling and protein synthesis are necessary for the acute anxiolytic effect of OXT in the PVN of male $[4,20]$ and virgin female [5] rats. In addition, the acute anxiolytic activity of OXT in the PVN is enhanced under mild stress conditions [4] indicating an interaction of OXT and central stress regulation. Indeed, OXT has been found to reduce and delay the hypothalamic expression of corticotropin-releasing factor $(\mathrm{Crf})$ [22, 23], and reciprocal interactions with the anxiolytic [24, 25] transmembrane CRF receptor $2 \alpha$ (mCRFR $2 \alpha$ ) signaling in the PVN and bed nucleus of the stria terminalis have been described [26, 27].

OXT was found to be behaviorally effective not only in laboratory animals [3, 28], but also in humans, where synthetic OXT can be applied intranasally [29, 30]. In most human studies, OXT has been applied acutely so far, and, even at relatively high doses, persistent side effects have not been reported [31, 32]. However, we and others have found adverse effects on anxiety [33], fear [34], and social behaviors [35-37] after chronic OXT application, or otherwise artificially enhanced OXT signaling, in rodents. For example, we have recently observed a dose-dependent anxiogenic effect in mice following continuous intracerebroventricular (icv) infusion of OXT using osmotic minipumps, with a dose of $10 \mathrm{ng} / \mathrm{h}$ OXT increasing anxiety-like behavior after 14 days [33]. These adverse behavioral consequences were accompanied by a reduction in intracerebral OXTR expression $[33,35]$. In line with the described consequences of chronic OXT treatment and increased OXTR-mediated signaling, viral vector-induced overexpression of the OXTR in the lateral septum enhanced contextual fear in socially defeated mice [34]. Only in female rats with genetically determined high anxiety [38] and in lactating females [39], a beneficial anxiolytic effect of icv OXT infusion over 5 days was found. However, the molecular mechanisms underlying the adverse effects of chronic or prolonged OXT actions on anxiety, fear, or social behavior, in contrast to its beneficial acute effects, have mostly been disregarded, but ought to be carefully considered before OXT can be used as a treatment option for psychiatric disorders [28, 29, 40-42]. So far, the few human studies employing repeated intranasal administration of OXT over several days or weeks focused on social parameters and almost consistently reported a lack of major adverse side effects, such as self-reported anxiety or changes in blood pressure, osmotic homeostasis or bone metabolism [43, 44], but more detailed and targeted studies are missing.

Therefore, in the present study we addressed the molecular mechanisms causing the anxiogenic effect of chronic icv OXT treatment in rats. While we found that chronic OXT enhanced anxiety-like behavior in both male and female rats, the underlying mechanism appeared to be sexually dimorphic. Uniquely in males, chronic OXT recruited a so far unknown intracellular signaling pathway in the PVN downstream of the OXTR, which includes the MAPK-controlled phosphorylation of the transcription factor myocyte enhancer factor 2 isoform A (MEF2A) [45]. In more detail, all MEF2 isoforms are crucial transcription factors controlling basic cellular functions associated with learning and memory consolidation, dendrite morphogenesis, excitatory synapse formation in hippocampal neurons during development [46], and some variants are associated with autism spectrum disorder [47, 48]. The MEF2Aspecific phospho sites Ser408, Thr312, Thr319 assessed in this study have different transcriptional effects, with Ser408 being repressive, and $\mathrm{Thr} 312$ and $\mathrm{Thr} 319$ being transcription activators. Further downstream of MEF2A, we could reveal that chronic icv OXT induced alternative splicing of $C r f r 2 \alpha$ to its soluble form (sCRFR2 $\alpha$ ). Interestingly, chronic OXT also triggered the release of the splice variant sCRFR $2 \alpha$ into the cerebrospinal fluid (CSF), and we further found that sCRFR $2 \alpha$ levels in CSF positively correlated with anxiety-like behavior. As a final proof of the involvement of sCRFR $2 \alpha$ in the adverse behavioral consequences of chronic OXT treatment, we manipulated Crfr $2 \alpha$ splicing in favor of its soluble form and could confirm its anxiogenic regulatory capacity. Taken together, our data provide a mechanistic explanation of the 
anxiogenic effect of chronic OXT in male rats, and illustrate the intimate relationship between the OXT and CRF systems. Consequently, they challenge the concept of treating emotional or social dysfunctions with repetitive or chronic OXT application [40, 49-51], and forward sCRFR2 $\alpha$ as a novel target for the development of anxiolytics.

\section{Material and methods}

A detailed list of chemicals and material used in this study can be found in Supplementary Table S1. Primers and antibodies are listed in Supplementary Tables S2 and S3.

\section{Animals and husbandry}

Adult male and female Wistar rats (Charles River, Germany, 250-300 g) were housed under standard temperature- and humidity-controlled conditions with food and water ad libitum. All animal experiments were performed between 08:00-11:00 according to the ARRIVE guidelines [52] and recommendations from the National Institutes of Health, and approved by the government of Unterfranken, Germany. In all in vivo experiments, the experimenter was blind to the treatment. Group sizes were estimated upon power analysis, based on results from previous publications [5, 22, 33, 38]. Animals were randomly assigned to experimental groups, complying with equal mean body weight between groups. Pre-established exclusion criteria for animals included complications during surgery, poor histological quality, and general poor health condition.

\section{Chronic icv OXT infusion}

Osmotic minipumps (Alzet, model 1002, flow rate $0.25 \mu \mathrm{l} /$ h, 14 days) were filled with either vehicle (VEH; Ringer's solution, B. Braun Melsungen AG, Germany), $4 \mu \mathrm{M}$ or 40 $\mu \mathrm{M}$ OXT (Bachem, Bubendorf, Switzerland) to allow the infusion of $1 \mathrm{ng} / \mathrm{h}$ or $10 \mathrm{ng} / \mathrm{h}$ of OXT, and were implanted subcutaneously [38]. On day 13, rats were mildly stressed by 5-min exposure on the elevated platform [4, 53], and tested in the light-dark box (LDB) [15, 38] on day 14 . Another rat cohort was tested in the LDB on day 14 without prior platform exposure.

\section{Acute icv and local intra-PVN infusions}

Acute icv or intra-PVN infusions of VEH, OXT (icv: $100 \mathrm{ng} / 5 \mu \mathrm{l}$; local: $10 \mathrm{ng} / 0.5 \mu \mathrm{l}$ per side, corresponding to $20 \mu \mathrm{M}$ ), antisauvagine-30 (ASV, $500 \mathrm{ng} / 0.5 \mu \mathrm{l}$ per side; Tocris Bioscience, Bristol, UK) or stresscopin (SCP, $3 \mu \mathrm{g}$ / $0.5 \mu \mathrm{l}$ per side, $25 \mathrm{~min}$ prior testing; Phoenix
Pharmaceuticals, Inc., Burlingame, USA) were performed 7 days after stereotaxic implantation of guide cannulas targeting the region of interest and recovery as described before $[4,15,53]$.

\section{Infusion of GapmeRs or target site blockers (TSBs)}

In order to assess the behavioral consequences of selective manipulation of mCRFR $2 \alpha / \mathrm{sCRFR} 2 \alpha$ ratio, bilateral intraPVN $(-1.7 \mathrm{~mm}$ bregma, $\pm 0.3 \mathrm{~mm}$ lateral, $8.2 \mathrm{~mm}$ deep) infusions of locked nucleic acid antisense oligonucleotides (so-called GapmeRs), TSBs or scrambled control oligonucleotides $(0.5 \mathrm{nmol} / 0.5 \mu \mathrm{l}$, Qiagen, Hilden, Germany, Supplementary Material) were performed 7 days prior to LDB testing, and 8 days prior to testing in the open field (OF) and for social preference [54].

\section{Behavioral tests}

Anxiety-related behavior was assessed in the LDB, elevated plus-maze (EPM), or OF during 5-min sessions [4]. For behavioral specificity of OXT effects in the PVN, social motivation was tested in the social preference test [54]. Locomotion (distance traveled) was determined by Noldus EthoVision XT 14 software.

\section{Tissue, plasma, and organ processing}

After behavioral testing, brains were removed for regional protein and RNA isolation, histological verification of cannula placement or in situ hybridization (ISH). For CSF sampling from the cisterna magna, rats were terminally anaesthetized with urethane, before trunk blood was collected for analysis of ACTH and corticosterone levels. The weights of adrenal glands, heart, and thymus were taken, and oil-red staining of lipid vesicles in the adrenal cortex was conducted [55].

\section{Cell lines and primary cultures}

Authentication of rat hypothalamic H32 cells [56] was executed on the basis of OXTR sequencing, morphology, and marker gene expression. Potential mycoplasma contamination was assessed on a regular basis. Cells were cultured in DMEM/F12 (Sigma-Aldrich, Darmstadt, Germany) with 10\% heat inactivated FBS advanced (Capricorn, Ebsdorfergrund, Germany), and penicillin/streptomycin (Sigma-Aldrich, Darmstadt, Germany). Cells were sub-cultured by gentle trypsinization $\left(\mathrm{Gibco}^{\mathrm{TM}}\right.$, Thermo Fisher Scientific, Waltham, USA) at $80 \%$ confluence. For transcriptional analyses, cells were seeded at a density of $3 \times 10^{6}$ cells in a $25 \mathrm{~cm}^{2}$ cell culture dish the day before experiment, pre-incubated in 
serum-free stimulation medium for $1 \mathrm{~h}$ and stimulated with the respective treatment.

Primary neuronal and glial cultures were obtained from embryonic day 18 rat hypothalami [22].

\section{In silico analysis of MEF2 targets}

Analysis of potential MEF2 targets by assessment of DNA binding regions was performed using the Geneious prime software (Geneious prime 2019.0.3; https://www.geneious. com).

\section{MEF2A knockdown studies}

$\mathrm{H} 32$ cells were seeded $24 \mathrm{~h}$ prior to transfections. For MEF2A knockdown, siRNA or scrambled RNA (scrRNA) as control (1 nM; \#SR504191, OriGene, Rockville, USA, Supplementary Material) were transfected with Lipofectamine RNAiMAX (Invitrogen by Thermo Fisher Scientific, Waltham, USA) and incubated for $72 \mathrm{~h}$ at $37^{\circ} \mathrm{C}$ and $5 \%$ $\mathrm{CO}_{2}$. After $48 \mathrm{~h}$, cells were stimulated with either $100 \mathrm{nM}$ OXT or VEH for another $24 \mathrm{~h}$.

\section{Chromatin-IP}

H32 cells were stimulated as described above, MEF2ADNA complexes were fixed for $10 \mathrm{~min}$, lysed (Supplementary Material), sheared by sonication, precleared with Sepharose beads, and MEF2A complexes isolated with a specific MEF2A antibody (Supplementary Material). DNA fragments were identified by qPCR with primers directed against $C r f r 2$-specific MEF2A binding sequences (Supplementary Material).

\section{Nano-Glo ${ }^{\circledR}$ HiBiT extracellular detection system}

The integration site of the HiBiT-containing Ultramer ${ }^{\circledR}$ ssDNA donor sequence was directly upstream of Exon 6 of the Crfr2 $\alpha$ gene (Supplementary Material). The donor sequence was delivered together with the RNP complex (Alt-R ${ }^{\circledast}$ CRISPR-Cas9 system, IDT, Coralville, USA) by using Lipofectamine ${ }^{\mathrm{TM}}$ RNAiMAX. Membrane-bound CRFR $2 \alpha$ (mCRFR2 $\alpha)$ was visualized using the Nano$\mathrm{Glo}^{\circledR}$ HiBiT Extracellular Detection System according to the manufacturer's instructions (Promega, Mannheim, Germany). Luminescence was measured at the GloMax Explorer (Promega, Mannheim, Germany).

\section{Immunofluorescent labeling for co-localization of sCRFR2a, OXTR, and OXT in OXTR-reporter mice}

OXTR-reporter mouse brains (OXTR-Venus [12]) were immunostained (Supplementary Material). Colocalization of sCRFR2 $\alpha$, OXTR and OXT was analyzed using the BioVoxxel Version of Fiji and plugin JACoP. Antibody specificity was assessed by pre-incubation with immunizing peptide, and in knockdown and overexpression systems (Supplementary Fig. S1A-D).

\section{Immunocytochemistry}

To visualize sCRFR $2 \alpha$ expression, immunocytochemistry in primary hypothalamic cells was performed (Supplementary Material).

\section{Western Blot and Dot Blot analysis}

For Dot Blot analysis, $10 \mu \mathrm{g}$ of total protein was pipetted onto a Nitrocellulose membrane, allowed to dry and processed identical to the Western Blot protocol previously described [20, 22, 45]. Detection was performed using a specific sCRFR $2 \alpha$ antibody [57]. Loading was controlled by Ponceau red staining.

\section{ISH for OXT MRNA}

To assess hypothalamic OXT mRNA, ISH was conducted [33] using a ${ }^{35}$ S-labeled probe specific for rats and mice (Supplementary Material).

\section{Receptor autoradiography for OXTR and V1aR binding}

To quantify hypothalamic OXTR and V1aR binding, receptor autoradiography was performed on $16-\mu \mathrm{m}$ coronal cryostat sections [39] (Supplementary Material).

\section{ACTH and corticosterone analyses}

Plasma samples were assayed using ELISA (IBL, Hamburg, Germany) for ACTH (sensitivity $0.22 \mathrm{pg} / \mathrm{ml}$, intra-assay and inter-assay coefficients of variation $\leq 7.1 \%$ ) and corticosterone (sensitivity $<1.63 \mathrm{nmol} / \mathrm{l}$, intra-assay and interassay coefficients of variation $\leq 6.35 \%$ ).

\section{RNA isolation for qPCR and PCR array}

To analyze mRNA expression of target genes in punches from PVN, hippocampus, and prefrontal cortex, RNA was isolated as described before [22].

To isolate RNA from stimulated H32 cells, the medium was aspirated, cells were washed with PBS, and RNA was isolated according to manufacturer's instruction (Macherey Nagel, Düren, Germany).

$300 \mathrm{ng}$ of total RNA per sample were used for reverse transcription into cDNA using Super Script IV First strand 
Synthesis System for RT-PCR (Invitrogen; Supplementary Material). The custom $\mathrm{RT}^{2}$ PCR array (330171 CLAR25389) was purchased from Qiagen (Hilden, Germany) and pipetted according to the manufacturer's protocol.

\section{TransAM MEF2 binding kit}

Protein samples were collected according to the manufacturer's protocol (Active Motif, Rixensart, Belgium), and $20 \mu \mathrm{g}$ protein was loaded onto the pre-coated 96 well plate. MEF2A and MEF2C subform-specific antibodies from OriGene/Acris (Rockville, USA; Supplementary Material) were used. Fluorescence was determined at $450 \mathrm{~nm}$ in a plate reader (FluoStar Optima, BMG LABTECH, Ortenberg, Germany).

\section{Statistical analysis}

Parametric one-way (factor treatment) or two-way (factors treatment $x$ time) analysis of variance (ANOVA), followed by Holm Sidak post hoc correction, were performed for statistical analyses of behavioral and molecular experiments (Sigma Plot, version 11.0.0.75, Systat Software). Data sets were analyzed for normal distribution using the Shapiro-Wilk test. Non-parametric data was analyzed by Kruskal-Wallis ANOVA on ranks and Tukey post hoc test. Separate parametric $t$-test between two groups or nonparametric Mann-Whitney U tests were performed. Data outliers were defined as above or below mean $\pm 2 \mathrm{x}$ standard deviation. Statistical significance was accepted at $p<0.05$. Data are presented as mean \pm standard error of the mean (SEM).

\section{Results}

\section{Chronic OXT dose-dependently induces an anxiogenic phenotype}

After 14 days of chronic icv OXT infusion, and one day after 5-min exposure to the elevated platform, rats were tested in the LDB (Fig. 1A). Compared to VEH controls, males treated with the high $(10 \mathrm{ng} / \mathrm{h})$, but not low $(1 \mathrm{ng} / \mathrm{h})$, dose of OXT spent less time in the light box, demonstrating an anxiogenic effect of chronic OXT (Fig. 1B, C). The increase in anxiety contrasted with the anxiolytic effect seen after acute OXT infusion into the PVN under otherwise identical experimental conditions (Fig. 1D, E), and with the absence of any effect on anxiety-like behavior after acute icv infusion (Supplementary Fig. S2A [38]). The anxiogenic phenotype was transient and waned within five days after termination of chronic OXT infusion (Supplementary
Fig. S2B). In females, the lower dose increased anxiety-like behavior, indicating seemingly higher sensitivity, while the higher dose was without effect in the LDB (Supplementary Fig. S2C). Chronic OXT-induced anxiogenesis was not accompanied by changes in locomotor activity, neither in males nor in females (Supplementary Table S4). Importantly, chronic OXT had no effect on the expression of hypothalamic OXT and AVP, their receptors, or on OXTR and $\mathrm{V} 1 \mathrm{aR}$ binding in various brain regions (Supplementary Table S5). Also, plasma ACTH and corticosterone levels, as well as other peripheral parameters remained unchanged after chronic OXT (Supplementary Tables S5 and S6 and Supplementary Fig. S2D).

\section{Chronic OXT treatment recruits the transcription factor MEF2A}

In PVN protein extracts, we observed increased phosphorylation, reflecting activation, of the MAP kinases MEK1/2 (at 1 and $10 \mathrm{ng} / \mathrm{h}$ ) and ERK1/2 (at $10 \mathrm{ng} / \mathrm{h}$ ) after chronic OXT infusion in males, whereas no such activation was found in females (Fig. 2A, B, Supplementary Fig. S3A, B). Moreover, chronic OXT $(10 \mathrm{ng} / \mathrm{h})$ resulted in elevated total protein levels of MEF2A (Fig. 2C), and this was accompanied by increased MEF2A activity, as indicated by increased MEF2A DNA binding in PVN tissue lysates of male rats (Fig. 2D, Supplementary Fig. S3C). The observed phosphorylation of the transcription activation sites $\mathrm{Thr} 312$ and Thr319 reflects elevated MEF2A activity, whereas the MEF2A inhibitory site Ser408 was dephosphorylated (Fig. 2E). Thus, chronic OXT activates MEF2A in the PVN of male rats (Supplementary Table S5 and Supplementary Fig. S3D). In contrast, acute icv OXT failed to enhance MEF2A activity (Supplementary Fig. S3E). Thus, OXTRcoupled signaling underlying the acute anxiolytic effect in the PVN does not involve the activation of MEF2A (Fig. 2D).

Five days after chronic OXT infusion had ended, MEF2A-DNA binding capacity was similar to that seen in VEH-treated rats (Fig. 2D), indicating that MEF2A activation is reversible. The activation of MEF2A in the PVN of chronically OXT-infused male rats appeared to be highly specific, as none of the other related kinases tested, including p38, p90rsk, and MSK, showed any significant changes in phosphorylation (Fig. 2F). In addition, the phosphorylation pattern of the closely related MEF2C, strongly expressed in the PVN and linked to OXTR signaling [58], remained unchanged at Ser59, the regulatory site inducing DNA binding (Fig. 2F). Consequently, DNA binding of MEF2C remained unaffected in the group treated with $10 \mathrm{ng} / \mathrm{h}$ OXT (Supplementary Fig. S3F).

In conclusion, chronic central infusion of high OXT results in MEF2A activation in the PVN of male rats, and 

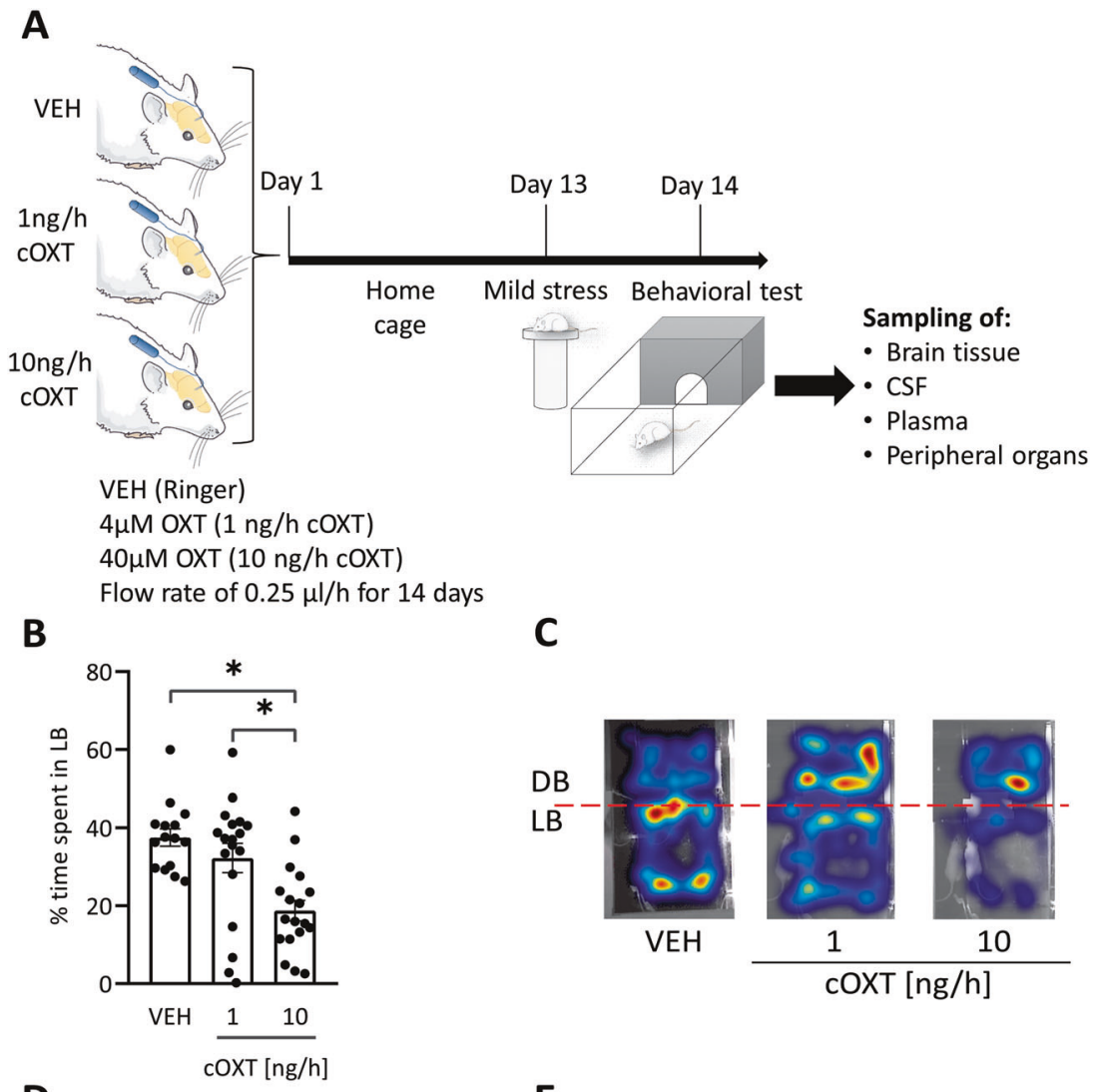

D
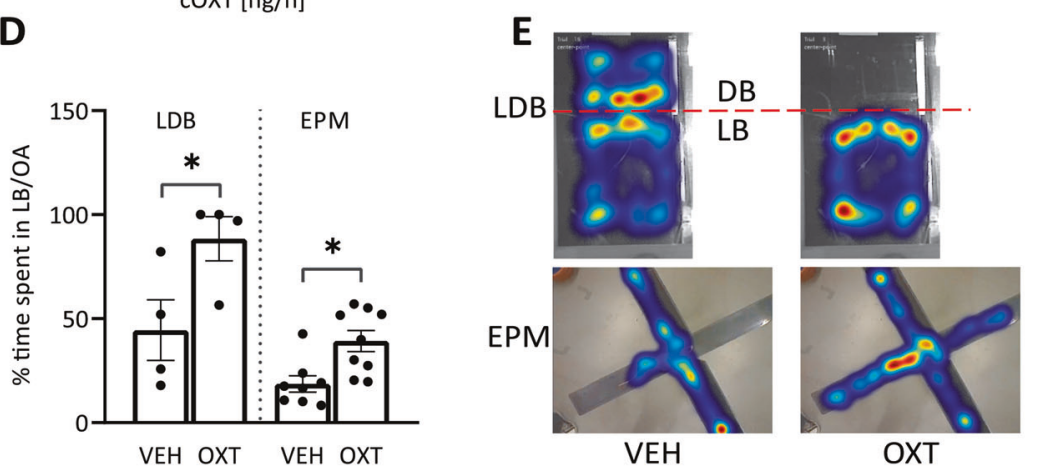

Fig. 1 Chronic icv OXT infusion increases anxiety in male rats. A Schematic of the chronic OXT (cOXT) infusion paradigm (created with BioRender.com). Osmotic minipumps (flow rate $0.25 \mu \mathrm{l} / \mathrm{h}$, infusion duration 14 days) were filled with vehicle (VEH), 4 or $40 \mu \mathrm{M}$ OXT, corresponding to 1 and $10 \mathrm{ng} / \mathrm{h}$ of OXT release rates, respectively, subcutaneously implanted and connected to the lateral ventricle of rats via polyethylene tubing. Day 1 marks the start of infusions. After 13 days, rats were mildly stressed by exposure to the elevated platform (EPF) for $5 \mathrm{~min}$, and tested in the light-dark box (LDB) on day 14 . Brain samples were collected immediately after LDB exposure. B cOXT decreased the time spent in the light box in a dosedependent manner. Shown is the percentage of time spent in the lit box

increased anxiety-related behavior. However, recruitment of MEF2A does not underlie the anxiogenic effect induced by infusion of the low dose of OXT in virgin female rats. Thus, the intracellular mechanisms causing anxiogenesis in females are distinct from those in males, and need further investigation.

(LB). Data are represented as mean \pm SEM. $\mathrm{F}(2 ; 50)=10.131 ; p<$ $0.001 ;$ Holm-Sidak $* p<0.001$ vs VEH; $n(\mathrm{VEH})=15, n(1 \mathrm{ng} / \mathrm{h}, 10 \mathrm{ng} /$ $\mathrm{h})=18$. C Representative heat maps of rat location in the LDB; treatments as described in B. D Acute bilateral infusion of OXT (acOXT; $20 \mu \mathrm{M}, 0.01 \mathrm{nmol} / 0.5 \mu \mathrm{l}$ per side) into the paraventricular nucleus (PVN) reduced anxiety-related behavior. Male rats were tested in the LDB or elevated plus-maze (EPM) $10 \mathrm{~min}$ after infusion, and 24 $\mathrm{h}$ after EPF exposure. Shown is the percentage of time spent in the LB or open arm (OA). Data are represented as mean \pm SEM. One-tailed Student's $t$ test, $p<0.01, \mathrm{df}=6 ; n(\mathrm{VEH})=4, n(\mathrm{acOXT})=4 . \quad \mathbf{E}$ Representative heat maps of rat location in the LDB and EPM after intra-PVN VEH or acOXT treatment.

\section{MEF2A shifts the expression of membrane-bound to soluble CRFR2 $a$ in the PVN}

To identify potential MEF2A target genes, we used a custom-designed PCR array that targets genes in the PVN that 1) are related to MEF2A functions, such as synaptic 

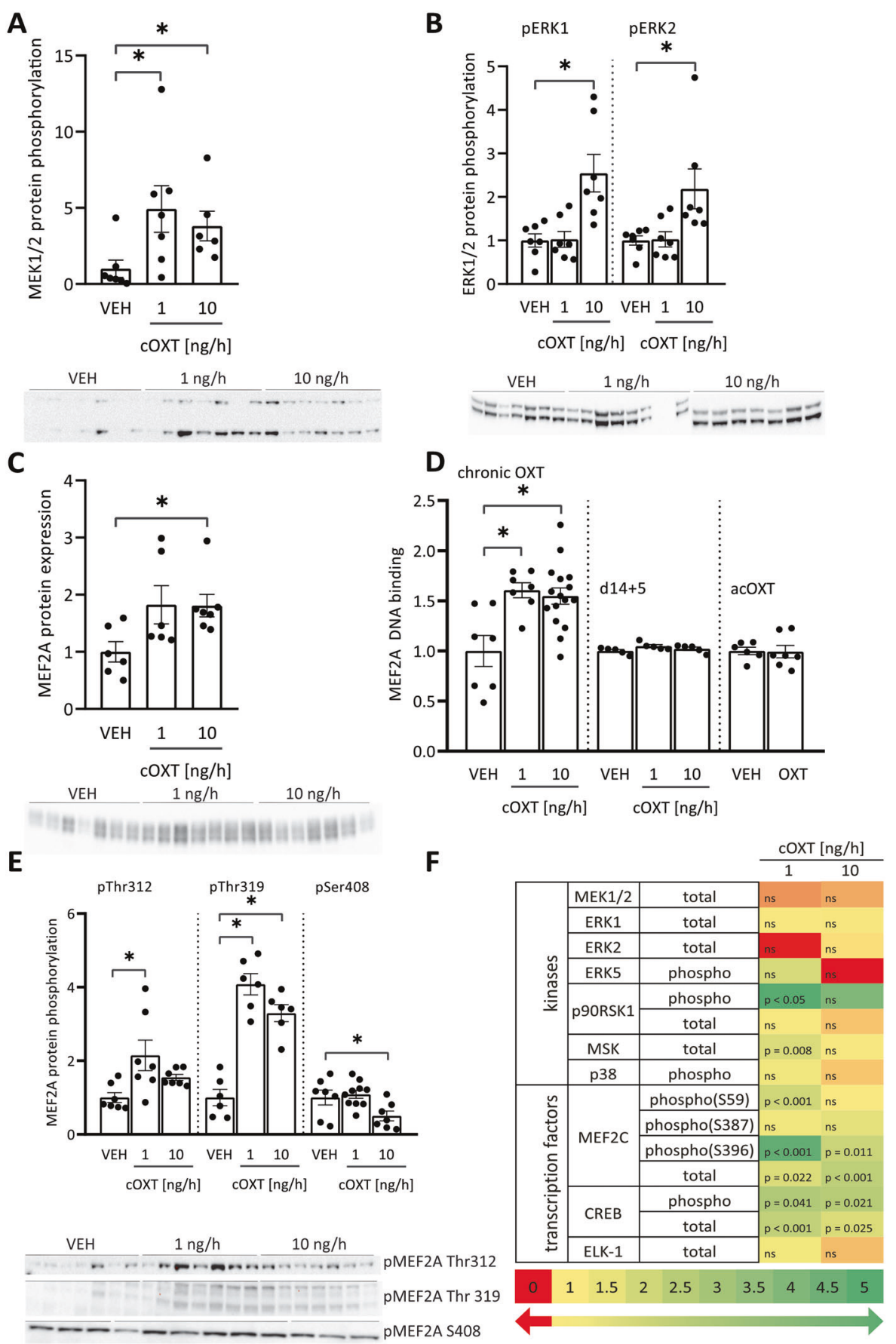

connectivity or neuronal plasticity, 2) contain one or more MEF2A binding sequences, and 3) have been associated with stress- or anxiety-like behaviors. After high chronic OXT treatment, we found distinct alterations in gene expression of closely related genes, of which those of membrane-bound and soluble CRFR2 $\alpha$ were particularly striking (Fig. 3A), because of the known OXT and CRF interactions [22, 59], as well as the involvement of CRF in stress and anxiety [25, 60-62]. The expression of membranebound CRFR2 $\alpha$ (mCRFR2 $\alpha$; Fig. 3A) was reduced, whereas that of the alternative splice variant, soluble CRFR2 $\alpha$ (sCRFR2 $\alpha$ ), was increased in PVN tissue of chronic OXTtreated male, but not female (Supplementary Fig. S4A), rats, when compared with VEH-treated animals. Alternative splicing was confirmed by endpoint PCR demonstrating that $s C r f r 2 \alpha$ expression, which was below the detection limit in VEH controls, is effectively induced after chronic OXT (Fig. 3B upper panel). At the protein level, OXT-treated males expressed more sCRFR $2 \alpha(88.3 \%)$ in proportion to mCRFR2 $\alpha$ (11.7\%; Fig. 3B lower panel and 3 C). No such 
Fig. 2 Recruitment of MAPK and MEF2A by chronic OXT infusion in the PVN of male rats. A cOXT at low and high doses increased MEK1/2 phosphorylation in the PVN after 14 days. Data are represented as mean \pm SEM. Kruskal-Wallis $H=8.396 ; p=0.015$; Dunn's Method ${ }^{*} p<0.05$ vs VEH; $n(\mathrm{VEH} ; 1 \mathrm{ng} / \mathrm{h})=7, n(10 \mathrm{ng} / \mathrm{h})=$ 6. B ERK1/2 phosphorylation was increased by $10 \mathrm{ng} / \mathrm{h}$ cOXT treatment; $n(\mathrm{VEH} ; 1 \mathrm{ng} / \mathrm{h} ; 10 \mathrm{ng} / \mathrm{h})=7 ; \mathrm{pERK} 1: \mathrm{F}(2 ; 20)=9.672 ; p=$ 0.001 ; Holm-Sidak $* p=0.001 \mathrm{VEH}, 1 \mathrm{ng} / \mathrm{h}$ vs $10 \mathrm{ng} / \mathrm{h}$; pERK2: Kruskal-Wallis $H=10.293 p=0.006$; Tukey Test VEH vs $10 \mathrm{ng} / \mathrm{h}$ ${ }^{*} p<0.05,1 \mathrm{ng} / \mathrm{h}$ vs $10 \mathrm{ng} / \mathrm{h} * p<0.05$. C MEF2A total protein expression increased in PVN lysates of $10 \mathrm{ng} / \mathrm{h}$ cOXT-treated male rats. Kruskal-Wallis $H=7.156, p=0.028$; Dunn's Method $* p<0.05$ $\mathrm{VEH}$ versus $10 \mathrm{ng} / \mathrm{h} ; n(\mathrm{VEH})=6, n(1 \mathrm{ng} / \mathrm{h})=6, n(10 \mathrm{ng} / \mathrm{h})=7 . \mathbf{D}$ MEF2A DNA binding activity increased in PVN lysates after 14 days of chronic OXT at both doses and mild stress. Values are normalized to VEH. $\mathrm{F}(2 ; 29)=8.262, p=0.002$, Holm-Sidak $* p=0.05$ vs VEH; $n(\mathrm{VEH})=7, n(1 \mathrm{ng} / \mathrm{h})=7, n(10 \mathrm{ng} / \mathrm{h})=16$. In contrast to 14 days of cOXT treatment, MEF2A binding activity returned to basal, 5 days after the infusion had stopped (cOXT d14 +5$)$. Data are represented as fold changes in DNA-binding activity \pm SEM. $F(2,14)=2.316, p=$ $0.141 ; n(\mathrm{VEH})=5, n(1 \mathrm{ng} \mathrm{cOXT})=5, n(10 \mathrm{ng} \mathrm{cOXT})=5$. No effects of acute intra-PVN OXT infusions have been observed on local MEF2A binding activity. $t=0.0938$; two-tailed $p$ value $=0,927, n$ $(\mathrm{VEH})=6, n(\mathrm{OXT})=7 ; n$ for all groups $n=7$. E Phosphorylation of Thr312 and Thr319 within MEF2A increased in both the high and the low treatment group, while Ser408 phosphorylation decreased after cOXT at $10 \mathrm{ng} / \mathrm{h}$. pMEF2A Thr312: Kruskal-Wallis $H=9,106, p=$ 0.011 ; Tukey Test VEH vs $1 \mathrm{ng} / \mathrm{h} * p<0.05 ; n(\mathrm{VEH})=7, n(1 \mathrm{ng} / \mathrm{h})=$ $7, n(10 \mathrm{ng} / \mathrm{h})=7$. pMEF2A Thr319: $F(2 ; 17)=41.139 ; p<0.001$; Holm-Sidak $* p=0.05$ VEH versus $1 \mathrm{ng} / \mathrm{h}$ and $10 \mathrm{ng} / \mathrm{h}$, and $1 \mathrm{ng} / \mathrm{h}$ versus $10 \mathrm{ng} / \mathrm{h} ; n(\mathrm{VEH})=6, n(1 \mathrm{ng} / \mathrm{h})=6, n(10 \mathrm{ng} / \mathrm{h})=6$. pMEF2A Ser408: $F(2 ; 23)=4.614 ; p=0.022 ;$ Holm-Sidak $* p=0.033$ VEH versus $10 \mathrm{ng} / \mathrm{h}$ cOXT; $n(\mathrm{VEH})=7, n(1 \mathrm{ng} / \mathrm{h})=10, n(10 \mathrm{ng} / \mathrm{h})=7 . \mathbf{F}$ Heat map of expression and phosphorylation levels of second messenger kinases and transcription factors downstream of the OXTR as analyzed by Western blot. Fold change below 1 (red) indicates downregulation, fold change of 1 (yellow) indicates no change, fold change bigger than 1 indicates upregulation (green). $p$ values vs VEH included; n.s. not significant; $n$ for all groups $n=7$.

effect was seen after an acute local administration of OXT (Fig. 3D). In silico analysis revealed that the coding sequence of the $C r f r 2 \alpha$ gene harbors seven potential MEF2A binding sites, two of them present within Exon 6 (base pairs 791-800 and 908-917). We performed ChIP analysis (Supplementary Fig. S4B) with H32 cells, which express MEF2A, OXTR (Supplementary Fig. S1A, B) and CRFR2 $\alpha$ and found MEF2A binding to the Crfr $2 \alpha$ gene especially within Exons 2 and 6 (Supplementary Fig. S4B). Furthermore, selective MEF2A knockdown by means of siRNA strongly reduced both mCRFR $2 \alpha$ and sCRFR $2 \alpha$ expression in $\mathrm{H} 32$ cells, highlighting the necessity of MEF2A to induce Crfr $2 \alpha$ gene transcription (via binding to Exon 2) and to promote alternative splicing (via binding to Exon 6; Fig. 3E). In confirmation of the presence of the OXTR-MEF2ASCRFR $2 \alpha$ cascade within OXTR-expressing PVN neurons, we found that OXTR (as revealed by a Venus signal) and SCRFR $2 \alpha$ are partially co-expressed in the PVN of OXTR reporter mice [12], whereas almost no co-expression of sCRFR2 $\alpha$ with V1aR or V1bR was detectable (Fig. 3F-I).

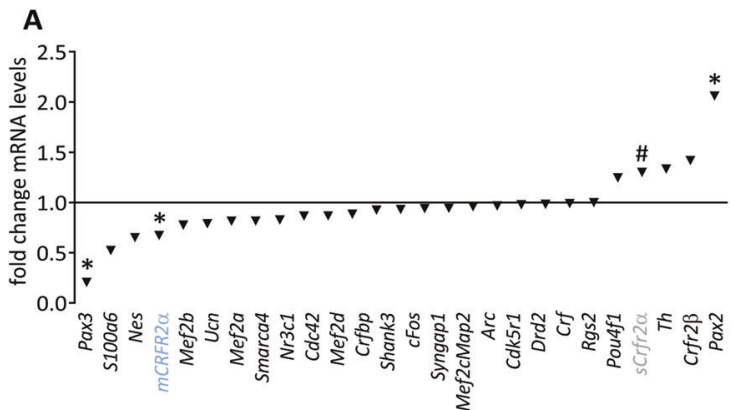

B

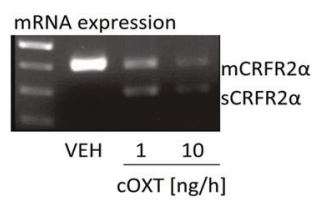

Protein expression

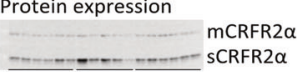

VEH $\frac{110}{\text { cOXT }[\mathrm{ng} / \mathrm{h}]}$

.

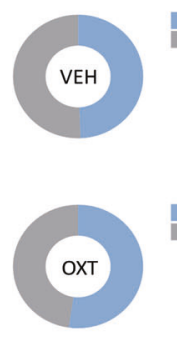

$49.42 \%$ mCRFR2 $50.58 \%$ sCRFR2 $\alpha$

E
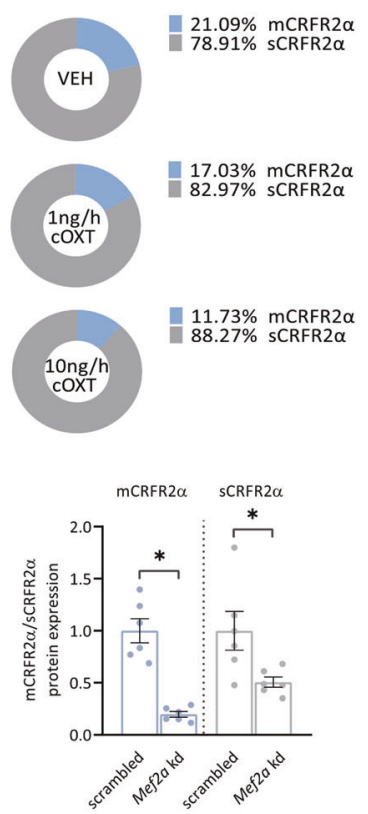

$\mathbf{F}$

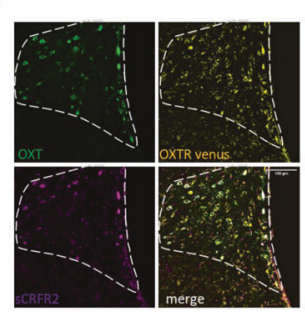

G

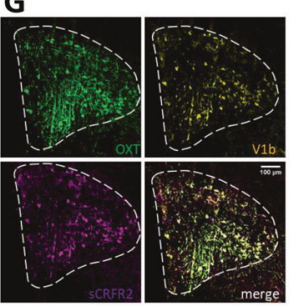

H OXTR/sCRFR2 $\alpha$ colocalization PCC 0.486 MOC (fraction of SCRFR2

I V1a/sCRFR2 $\alpha$ colocalization

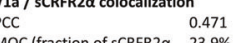
MOC (fraction of SCRFR $2 \alpha \quad 23.9 \%$ overlapping with OXTR) OXT / sCRFR2 $\alpha$ colocalization MOC (fraction of SCRFR2 $\alpha \quad 0.724$ MOC (fraction of SCRF
overlapping with OXT)

V1b / sCRFR2 $\alpha$ colocalization

MOC (fraction of SCRFR2 $\alpha \quad 0.717$ overlapping with $\mathrm{V} 1 \mathrm{~b}$ )

\section{Chronic OXT promotes the release of SCRFR2a in vitro}

To identify and visualize mCRFR $2 \alpha$ in $\mathrm{H} 32$ cells, we integrated a spliceable tag (HiBiT) into Exon 6 of $C r f r 2 \alpha$ by means of CRISPR-Cas9. This tag was visualized by adding the $\mathrm{LgBiT}$ substrate to the cell culture medium (Fig. 4A). The luminescent signal that forms following binding of LgBiT and HiBiT detects mCRFR $2 \alpha$ in live cells. We found 
Fig. 3 MEF2A-dependent regulation of OXT receptor target genes after cOXT treatment. A PCR array: Expression of MEF2A-regulated candidate genes after $10 \mathrm{ng} / \mathrm{h}$ cOXT treatment. Data calculated by $\Delta \Delta \mathrm{CT}$ and presented as fold change vs. VEH. Fold changes $>1$, upregulated mRNA expression, fold changes $<1$, downregulated mRNA expression. $n(\mathrm{VEH})=5, n(10 \mathrm{ng} / \mathrm{h} \mathrm{cOXT})=6$. Pax3 $* p=0.021, C r f r 2 \alpha * p=0.02, s C r f r 2 \alpha{ }^{\#} p=0.07, \operatorname{Pax} 2 * p=$ 0.05. B Upper panel: Representative example of 3 male rat PVN cDNA samples showing $m C r f r 2 \alpha$ (upper band, $400 \mathrm{bp}$ ) in VEH-treated animals, and $m C r f r 2 \alpha / s C r f r 2 \alpha$ (lower band, $300 \mathrm{bp}$ ) expression in the cOXT treatment groups. Lower panel: Western Blot of mCRFR $2 \alpha$ $(\sim 50 \mathrm{kDa})$ and sCRFR2 $\alpha(\sim 30 \mathrm{kDa})$ levels after VEH, 1 or $10 \mathrm{ng} / \mathrm{h}$ cOXT infusion and mild stress, using a polyclonal pan-CRFR2 antibody. C Ratio of mCRFR $2 \alpha$ and sCRFR $2 \alpha$ protein expression after cOXT and mild stress in male rats, shifting in the favor of sCRFR $2 \alpha$ following treatment. Data are represented as mean \pm SEM. $F(2 ; 15)=$ 5.311, $p=0.021$; Holm-Sidak $p=0.01910 \mathrm{ng} / \mathrm{h}$ vs VEH; $n(\mathrm{VEH})=$ $6, n(1 \mathrm{ng} / \mathrm{h})=5, n(10 \mathrm{ng} / \mathrm{h})=6$. D Treatment with acOXT had no effects on the ratio of mCRFR $2 \alpha / \mathrm{sCRFR} 2 \alpha$ protein expression in $\%$ in the PVN of male rats. Data are represented as mean \pm SEM. $t=0.784$ with 11 degrees of freedom, two-tailed $p$ value $=0.450 ; n(\mathrm{VEH})=6$, $n(\mathrm{OXT})=7$. $\mathbf{E}$ siRNA-mediated knockdown of MEF2A in H32 cells incubated with $100 \mathrm{nM}$ OXT decreased mCRFR $2 \alpha$ and sCRFR $2 \alpha$ protein levels, indicating a central role for MEF2A in the transcription of the CRFR2 gene. Data represented as mean \pm SEM. mCRFR $2 \alpha$ : Mann-Whitney Rank Sum Test $<0.001,{ }^{*} p=0.002$; sCRFR2 $\alpha$ : $t=$ 2.574 with 10 degrees of freedom; one-tailed $* p$ value $=0.0138$, both vs. respective scr (scrambled) control; $n(\mathrm{scr})=6, n(\mathrm{MEF} 2 \mathrm{~A} \mathrm{kd})=6 . \mathbf{F}$ Representative stainings showing co-localization of OXT-neurophysin I (green), sCRFR2 $\alpha$ (magenta), and OXTR-Venus (yellow) in the PVN (indicated by white dotted line) of male OXTR-Venus reporter mice. G Representative staining showing colocalization of OXT (green), sCRFR2 $\alpha$ (magenta), and V1bR (yellow) in the PVN of male Wistar rats. H Pearson and Manders overlap coefficient of OXTR, OXT, and SCRFR2 $\alpha$ positive neurons reveal substantial (45-64\%) overlap between the OXTR, OXT, and sCRFR $2 \alpha$. I Pearson and Manders coefficient reveal partial (24-37\%) overlap of V1a/b and sCRFR $2 \alpha$ in the PVN. OXT-neurophysin and sCRFR $2 \alpha$ show similar co-expression $(\sim 60 \%)$ in rats and mice, indicating a comparable expression pattern of the sCRFR2 $\alpha$ in both species.

that luminescence intensity dropped in OXT-treated cells $(100 \mathrm{nM}, 24 \mathrm{~h})$, indicating reduced membrane incorporation of mCRFR2 $\alpha$ (Fig. 4B). In parallel, sCRFR $2 \alpha$ content increased tenfold in the cell culture medium (Fig. 4C) demonstrating OXT-induced release of sCRFR $2 \alpha$ from H32 cells. In addition, staining of primary hypothalamic cells revealed punctate sCRFR $2 \alpha$ immunoreactivity in neurons and glial cells, reflecting vesicular localization (Fig. 4D).

\section{Changes in mCRFR2 $a / s C R F R 2 a$ ratio result in increased anxiety}

To determine whether sCRFR $2 \alpha$ is released in vivo, we sampled CSF from the cisterna magna of male rats and found detectable amounts of sCRFR2 $\alpha$ (Fig. 5A). In contrast, sCRFR2 $\alpha$ was not detectable in cerebellum tissue [57], confirming the specificity of the dot blot analysis. Next, we specifically knocked down the sCRFR $2 \alpha$ splice variant in the PVN by local infusion of GapmeRs [63] and

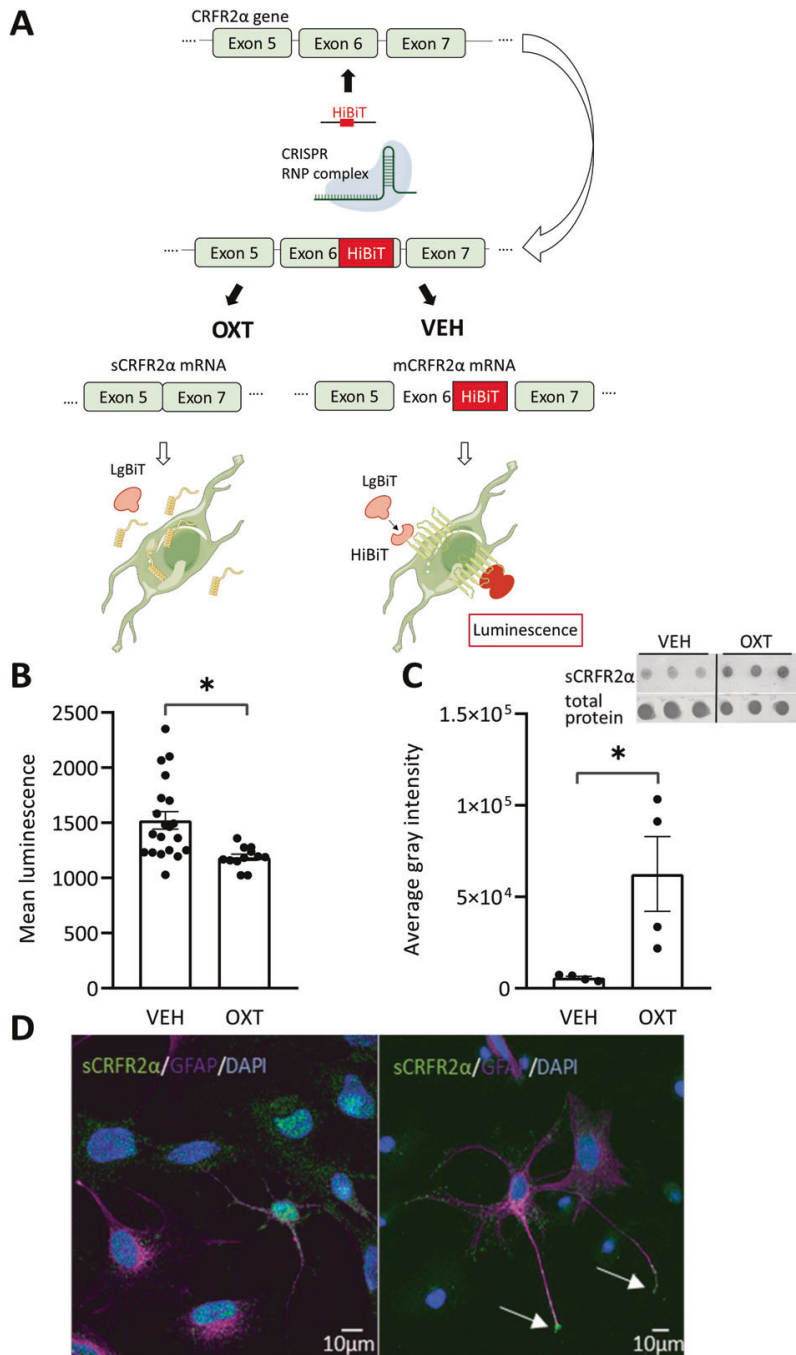

Fig. 4 Chronic OXT promotes the release of SCRFR2 $\alpha$ in vitro. A Schematic representation of HiBiT-mediated signaling in H32 cells stimulated with VEH or OXT for $24 \mathrm{~h}$ (created with BioRender.com). B Assessment of mCRFR $2 \alpha$ membrane expression by tagging the transmembrane domain encoded in Exon 6 with a HiBiT-tag. Membrane expression is indicated by luminescence caused by extracellular HiBiT-LgBiT interaction. Stimulation for $24 \mathrm{~h}$ with $100 \mathrm{nM}$ OXT decreased the luminescent signal, indicating alternative splicing of Exon 6 and, therefore, reduced membrane expression of CRFR2 $\alpha$. Data presented as absolute values of mean luminescence \pm SEM. Mann-Whitney Rank Sum Test, ${ }^{*} p \leq 0.001, n$ $(\mathrm{VEH})=20, n(\mathrm{OXT})=12$. C Cell culture supernatants taken from HiBiT-expressing cells (as shown in B) reveal sCRFR2 $\alpha$ release into the cell culture medium, which was 10 -fold higher after stimulation with $100 \mathrm{nM}$ OXT over $24 \mathrm{~h}$. Data shown as average gray intensity relative to total protein Ponceau red staining. Mann-Whitney Rank Sum Test, $* p=0.029 ; n(\mathrm{VEH} / \mathrm{OXT})=4$. Right panel: Representative Dot Blot of triplet sCRFR2 $\alpha$ staining and Ponceau red loading control. D Left panel: Representative images from rat hypothalamic mixed primary cultures stained for DAPI (blue), sCRFR2 $\alpha$ (green), and GFAP (magenta) reveal cytoplasmic distribution of sCRFR2a in neuronal cells (GFAP negative) and astrocytes (GFAP positive). Right panel: Accumulation of sCRFR $2 \alpha$ in end-boutons of astrocytic processes (white arrows) might indicate releasable pools. 
A

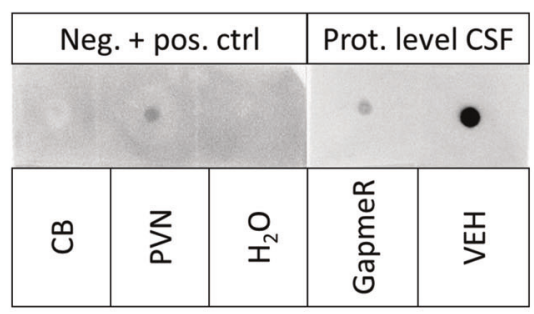

C

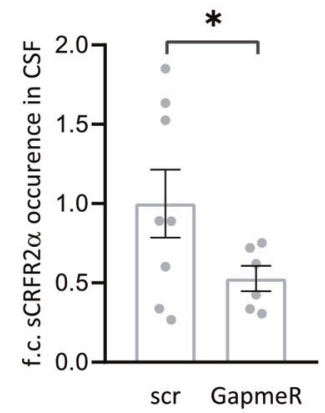

E

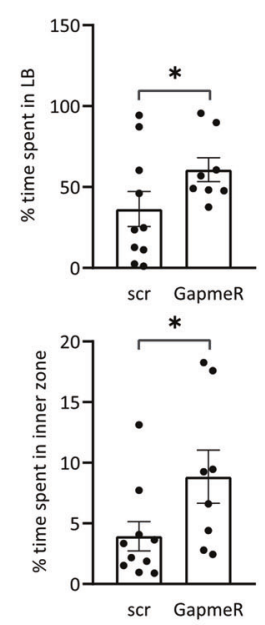

G

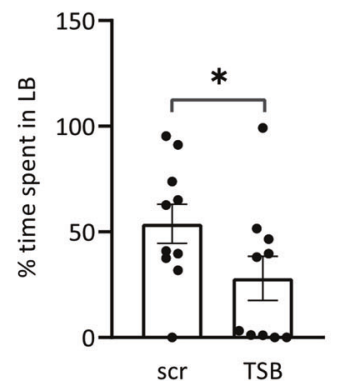

$\mathbf{F}$

H
B

Crfr2 $\alpha$ coding sequence (rat, NM_022714.1)

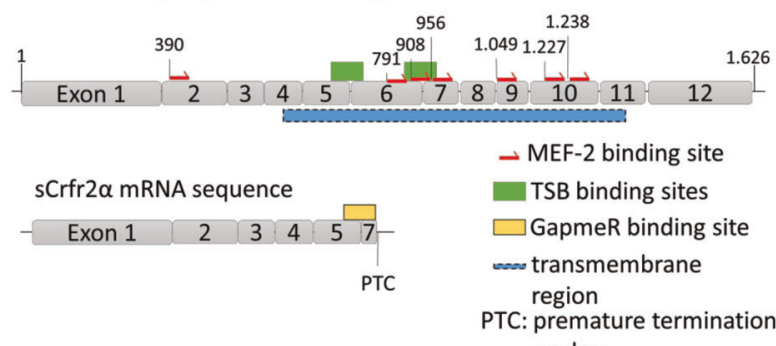

codon

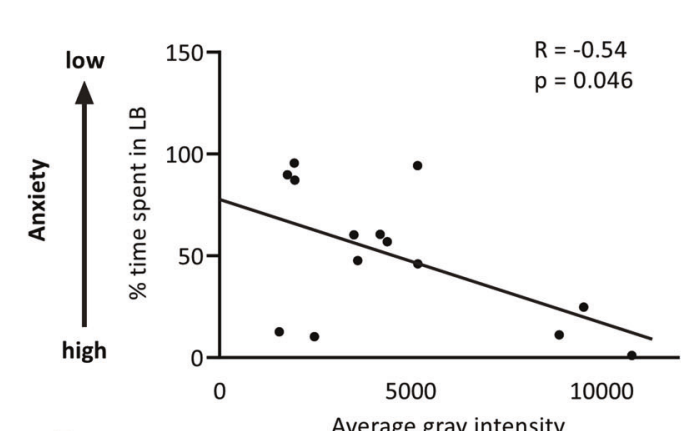

Average gray intensity
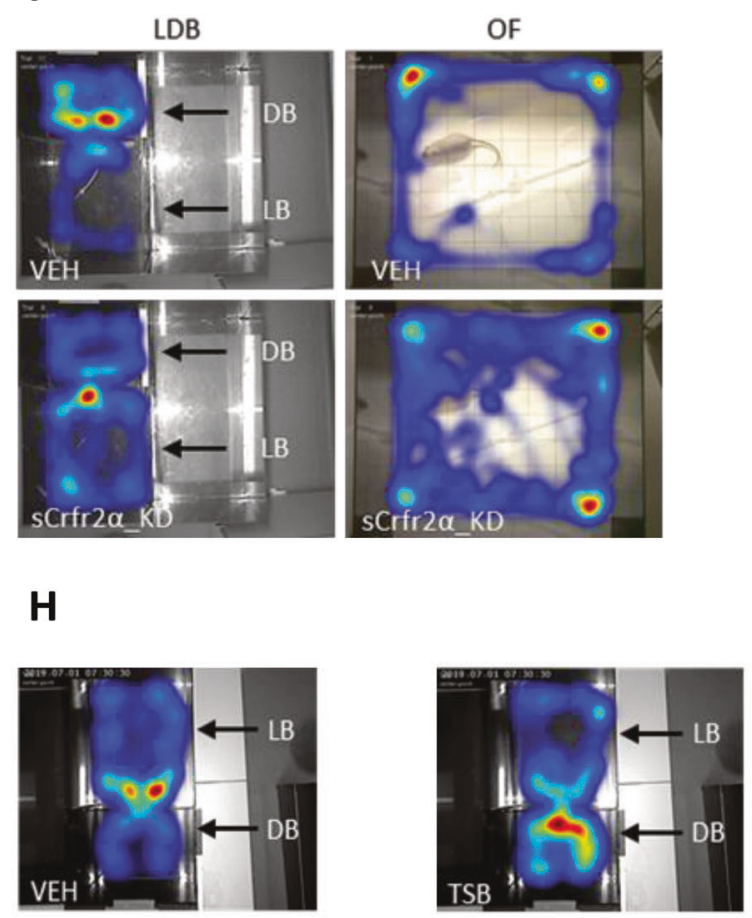

assessed whether the diminished availability of sCRFR $2 \alpha$ affects anxiety-related behavior. The GapmeRs were designed to bind the Exon 5-7 boundary, which is exclusively found in the mRNA of the soluble form of CRFR $2 \alpha$, so that specific knockdown of sCRFR $2 \alpha$ was achieved (Fig. 5B). Fluorescent labeling of the infused GapmeRs revealed predominantly intra-PVN staining, with some diffuse signal scattered in the adjacent, mostly dorsal hypothalamus, potentially representing cellular projections originating from the PVN (Supplementary Fig. S5A). Infusion of GapmeRs into the PVN caused a significant reduction of sCRFR2 $\alpha$ in the CSF after 7 days (Fig. 5C), which was accompanied by a reduction in anxiety-like behavior in the LDB reflected by an increased time spent in 
Fig. 5 Increased sCRFR2 $\alpha$ release underlies the anxiogenic effect of chronic OXT in combination with mild stress. A Representative picture of Dot Blot analysis (for detailed methodology see Supplementary Methods) of CSF (VEH and GapmeR) and control tissue protein lysates (cerebellum $=\mathrm{CB}$ as negative control, $\mathrm{PVN}$ as positive control, $\mathrm{H}_{2} \mathrm{O}$ ). For detection, the sCRFR $2 \alpha$-specific antibody (provided by Joan Vaughan [57]) was used at a dilution of 1:20.000 in 5\% BSA. B Schematic representation of the rat $\operatorname{Crfr} 2 \alpha$ gene, the transmembrane domain is indicated by a blue bar, including Exon 4 to Exon 11. Target site blocker (TSB) binding sites are indicated by green bars. Multiple MEF2 binding sites are indicated as red arrows. Exon 5/ 7 boundary GapmeR binding site in the $s C r f r 2 \alpha$ mRNA is indicated in yellow. C Infusion of GapmeRs targeting $s C r f r 2 \alpha$ bilaterally into the PVN of male rats reduced sCRFR $2 \alpha$ expression by $\sim 50 \%$ as assessed by Dot Blot in CSF samples. Data are shown as fold change in protein expression $\pm \mathrm{SEM}$. One-tailed Student's $t$ test, $t=1.828, \mathrm{df}=12,{ }^{*} p=$ $0.046 ; n(\mathrm{scr})=8, n(\mathrm{GapmeR})=6$. D Individual CSF sCRFR $2 \alpha$ signal intensity and \% time spent in LB correlate negatively $(R=-0.54$, ANOVA $F(1 ; 13)=4.946, p=0.046)$, suggesting that sCRFR $2 \alpha$ is anxiogenic. E GapmeR-induced reduction in sCRFR $2 \alpha$ increased the time spent in LB and inner zone of the $\mathrm{OF}$, indicating anxiolysis. Anxiety-like behavior was determined 7 (LDB) or 8 days (OF) after GapmeR infusion. Data are represented as mean percentage of time spent in the LB \pm SEM (one-tailed $t$-test $* p=0.0486$ ), and the mean percentage of time in the inner zone of the OF (Mann-Whitney Rank Sum Test $\left.U=16.000,{ }^{*} p=0.037\right) \pm$ SEM; $n(\mathrm{scr})=10, n($ GapmeR $)=$ 8. F Representative heat maps showing the distribution of rat presence in the light and dark compartment of the LDB or inner and outer zone in the OF test. G Infusion of TSBs bilaterally into the PVN of male rats and local induction of alternative splicing of $\operatorname{Crfr} 2 \alpha$ enhanced anxiety-like behavior of male rats in the LDB 7 days after infusion, demonstrating an anxiogenic effect of sCRFR $2 \alpha$. Data are represented as mean percentage of time spent in the LB \pm SEM. $t=1.843$; onetailed $t$-test $* p=0.0409 ; n(\mathrm{scr})=10, n(\mathrm{TSB})=10$. H Representative heat map of the distribution of rat presence in the LDB after VEH or TSB treatment.

the light box and increased exploration of the center area of the light box (Fig. 5D-F). In a complementary approach, we upregulated sCRFR $2 \alpha$ levels by TSBs, to promote alternative splicing of the $C r f r 2 \alpha$ mRNA to its shorter $s C r f r 2 \alpha$ form. This was achieved by targeting TSBs to the endogenous splice sites up- and downstream of Exon 6, thus enforcing the exclusion of Exon 6 from the pre-mRNA and inducing a frame shift to form a premature termination codon within Exon 7 (Fig. 5B). This process results in predominant $s C r f r 2 \alpha$ mRNA levels, at the expense of reduced $m C r f r 2 \alpha$ levels. TSB infusion bilaterally into the $\mathrm{PVN}$ resulted in increased anxiety-related behavior of male rats in the LDB (Fig. 5G, H).

Taken together, these results indicate that a low mCRFR $2 \alpha /$ high sCRFR $2 \alpha$ ratio in the PVN is associated with an anxiogenic phenotype. This was further substantiated by our observation of anxiolytic properties of mCRFR $2 \alpha$, as activation of mCRFR $2 \alpha$ by the agonist (SCP), and blocking mCRFR $2 \alpha$ with the antagonist (ASV) produced anxiolytic and anxiogenic effects, respectively (Supplementary Fig. S5B). Of note, the consequences of altered mCRFR $2 \alpha /$ sCRFR $2 \alpha$ ratio appear to be specific for anxiety, as social preference behavior, known to be promoted by OXT [9, 54], was not affected by GapmeRs or TSBs (Supplementary Fig. S5C). In summary, the identified OXTR-ERK1/2-MEF2A-sCRFR2 $\alpha$ intraneuronal pathway may underlie the anxiogenic effect of chronic OXT treatment in male rats.

\section{Discussion}

The brain OXT system has repeatedly been suggested as target for the treatment of psychopathologies associated with symptoms of anxiety [29, 40, 64]. Given that synthetic OXT therapy would most likely involve chronic or repeated application, detailed knowledge of the behavioral and molecular processes downstream of the OXTR after chronic OXT is indispensable.

In this study, we revealed that chronic icv OXT for 14 days increases anxiety-like behavior in male and virgin female rats in a sex- and dose-dependent manner. This central effect seems to be of transient nature, as it disappeared after a 5-day washout period. This together with the lack of an acute icv OXT effect on anxiety-like behavior indicates a reversible molecular mechanism within the brain that underlies the anxiogenic effect of chronic OXT. We showed that the anxiogenic effect in males is accompanied by the activation of a novel intracellular signaling pathway involving increased transcriptional activity of MEF2A, and subsequent alternative splicing of $C r f r 2 \alpha$ into its soluble, anxiogenic, form. The distinct role of SCRFR2 $\alpha$ in anxiety regulation was confirmed by targeted manipulations of $C r f r 2 \alpha$ splicing. While knockdown of sCRFR $2 \alpha$ within the PVN using GapmeRs reduced anxiety, local upregulation of alternative splicing of $C r f r 2 \alpha$ using TSBs increased anxiety, thus recapitulating the effect of chronic OXT. We further showed by CRISPR-Cas9-guided insertion of a HiBiT-tag into Exon 6 of the $C r f r 2 \alpha$ gene that chronic OXT reduced membrane expression of mCRFR $2 \alpha$ and induced the release of sCRFR $2 \alpha$ in vitro. In vivo, sCRFR $2 \alpha$ levels could be detected and quantified in the CSF, and were found to positively correlate with anxiety-like behavior. Although our results challenge the utility of chronic or repetitive OXT application as treatment option for anxiety-related disorders, we could identify sCRFR $2 \alpha$ as a novel target for diagnosis and pharmacological intervention of these disorders.

The CRFR $2 \alpha$ is predominantly expressed in the brain, with a few exceptions in peripheral organs $[65,66]$. One characteristic of the shorter and soluble splice variant, sCRFR $2 \alpha$, is its inability to incorporate into the cellular membrane due to the lack of the transmembrane domain and, therefore, high abundance in the cytosol from where it can be released into the extracellular space [57, 67]. Previous publications have suggested that the process of alternative splicing serves as a mechanism to control fulllength GPCR mRNA availability, which is in line with our 
data revealing the shifted ratio between sCRFR2 $\alpha /$ mCRFR2 $\alpha$ after chronic OXT treatment $[67,68]$.

We found that OXT-induced changes in MEF2A activity are involved in alternative splicing of $C r f r 2 \alpha$, in line with recent findings that MEF2A is part of a large complex of transcription and splicing-regulating factors, such as Brg1/ Brm, BAF47, BAF170, BAF155, or MyoD. These factors contribute to the correct transcription and immediate processing of the transcript $[69,70]$. Thus, our results support the hypothesis that transcription and alternative splicing are linked and co-dependent processes. Our data further suggest that activation of MEF2A via dephosphorylation at Ser408 is crucial to drive alternative splicing of $\operatorname{Crfr} 2 \alpha$, as this occurred only in the male $10 \mathrm{ng} / \mathrm{h}$ group and parallel to the increase in anxiety. Interestingly, chronic OXT did not activate MEF2A in female rats, although females appeared to be more sensitive to the anxiogenic effects of chronic OXT treatment than males. As a result, the mCRFR2 $\alpha /$ sCRFR $2 \alpha$ ratio remained unaltered in females after chronic OXT. Sexual dimorphism in OXT-induced anxiety has been described before and appears to be rooted in differential CRF signaling from OXTR-expressing interneurons in the prefrontal cortex [59]. In more detail, OXT-induced recruitment of CRF binding protein in the prefrontal cortex acts anxiolytic in a sex-specific manner, as CRF binding protein attenuates potentiation of postsynaptic layer $2 / 3$ pyramidal cell activity only in male mice and, thereby, brings about anxiolysis [59]. Although shorter in length, SCRFR $2 \alpha$ maintains its ability to bind the mCRFR $2 \alpha$ and CRFR1 ligands CRF, urocortin I and urocortin II with nanomolar affinity [57], and thus could prevent them from binding to mCRFR $2 \alpha$ [24]. Consequently, scavenging mCRFR $2 \alpha$ ligands by sCRFR $2 \alpha$ could weaken or prevent the anxiolytic signal conveyed by mCRFR $2 \alpha$, and promote anxiety-like behavior in males. However, in females, chronic OXT-induced anxiety appears to be mediated independent of MEF2A activation and sCRFR2 $\alpha$ production.

Importantly, we have detected SCRFR $2 \alpha$ in rat brain CSF and cell culture medium, proving that the release of sCRFR $2 \alpha$ into the extracellular space can be induced by OXT. The observed correlation between CSF sCRFR2 $\alpha$ levels and anxiety-like behavior further supports our hypothesis that the balance between soluble and membranebound CRFR2 $\alpha$ in the PVN in favor of the anxiogenic soluble splice variant is instrumental in promoting anxiety in male rats. Interestingly, we observed that brief exposure to a mild stressor, i.e., the elevated platform $24 \mathrm{~h}$ prior to testing, is required to induce anxiogenesis after chronic OXT treatment. As mild stress promotes the incorporation of anxiolytic mCRFR $2 \alpha$ into the membrane [71-73], chronic OXT might interfere with this process by shifting the mCRFR $2 \alpha / \mathrm{sCRFR} 2 \alpha$ ratio.
In conclusion, our study shows that chronic OXT dosedependently enhances anxiety-like behavior in males and females, which involves the activation of the transcription factor MEF2A and subsequent alternative splicing of Crfr $2 \alpha$ mRNA into the anxiogenic soluble form in male rats. Consequently, these findings together with previous data on adverse effects of chronic or repetitive OXT treatment in rodents and humans [33-37, 51] need to be carefully considered, before using chronic or repetitive administration of OXT for the treatment of psychopathologies. Our findings suggest that targeting sCRFR2 $\alpha$ synthesis and release may open a more promising avenue for future treatment options, particularly in men.

Acknowledgements We would like to thank Alon Chen (Weizmann Institute, Rehovut, Israel), Joan Vaughan (Salk Institute, La Jolla, California, USA) for providing the sCRFR $2 \alpha$ antibody and Prof. Dr. Harold Gainer (National Institutes of Health, Bethesda, Maryland, USA) for providing the OXT-neurophysin I antibody, Rodrigue Maloumby, Dr. Vinicius Oliveira, and Andrea Havasi for excellent technical help, and Dr. Carl-Philipp Meinung and Serena Gusmerini (all at University of Regensburg, Regensburg, Germany) for contributing scientific data. OXTR-reporter mouse brains were kindly provided by Prof. Dr. Katsuhiko Nishimori (Fukushima Medical University, Fukushima, Japan). This work was supported by the German Research Foundation GRK 2147 (IDN, BJ, OJB), JU3039/ 1-1 (BJ), NE 465/27-1 (IDN), NE 465/31-1 (IDN), NE 465/19-1 (IDN, EvdB), BO 1958/8-2 (OJB).

Author contributions Conceptualization, BJ, SP, DAS, EHvdB, IDN; Methodology, BJ, JW, MM, IB, IDN; Validation, JW, MM, IB, KK, MB, MR, AKS, AB; Investigation, JW, MM, IB, SP, MR, DL, SOR, KK, SS, FH, OJB, MB; Writing - Original Draft, JW, BJ; Editing, JW, IDN, BJ, EHvdB, SP, SOR, OJB, DAS; Funding acquisition and resources, IDN, BJ; Supervision, BJ, IDN. The funders had no role in study design, data collection and analysis, decision to publish, or preparation of the paper.

Funding Open Access funding enabled and organized by Projekt DEAL.

\section{Compliance with ethical standards}

Conflict of interest The authors declare no competing interests.

Publisher's note Springer Nature remains neutral with regard to jurisdictional claims in published maps and institutional affiliations.

Open Access This article is licensed under a Creative Commons Attribution 4.0 International License, which permits use, sharing, adaptation, distribution and reproduction in any medium or format, as long as you give appropriate credit to the original author(s) and the source, provide a link to the Creative Commons license, and indicate if changes were made. The images or other third party material in this article are included in the article's Creative Commons license, unless indicated otherwise in a credit line to the material. If material is not included in the article's Creative Commons license and your intended use is not permitted by statutory regulation or exceeds the permitted use, you will need to obtain permission directly from the copyright holder. To view a copy of this license, visit http://creativecommons. org/licenses/by/4.0/. 


\section{References}

1. Hokfelt T, Bartfai T, Bloom F. Neuropeptides: opportunities for drug discovery. Lancet Neurol. 2003;2:463-72.

2. Neumann ID, Landgraf R. Balance of brain oxytocin and vasopressin: implications for anxiety, depression, and social behaviors. Trends Neurosci. 2012;35:649-59.

3. Jurek B, Neumann ID. The oxytocin receptor: from intracellular signaling to behavior. Physiol Rev. 2018;98:1805-908.

4. Blume A, Bosch OJ, Miklos S, Torner L, Wales L, Waldherr M, et al. Oxytocin reduces anxiety via ERK1/2 activation: local effect within the rat hypothalamic paraventricular nucleus. Eur J Neurosci. 2008;27:1947-56.

5. Jurek B, Slattery DA, Maloumby R, Hillerer K, Koszinowski S, Neumann ID, et al. Differential contribution of hypothalamic MAPK activity to anxiety-like behaviour in virgin and lactating rats. PLoS One. 2012;7:e37060.

6. Bale TL, Davis AM, Auger AP, Dorsa DM, McCarthy MM. CNS region-specific oxytocin receptor expression: importance in regulation of anxiety and sex behavior. J Neurosci. 2001;21:2546-52.

7. Viviani D, Charlet A, van den Burg E, Robinet C, Hurni N, Abatis $\mathrm{M}$, et al. Oxytocin selectively gates fear responses through distinct outputs from the central amygdala. Science. 2011;333:104-7.

8. Knobloch HS, Charlet A, Hoffmann LC, Eliava M, Khrulev S, Cetin $\mathrm{AH}$, et al. Evoked axonal oxytocin release in the central amygdala attenuates fear response. Neuron. 2012;73:553-66.

9. Menon R, Grund T, Zoicas I, Althammer F, Fiedler D, Biermeier $\mathrm{V}$, et al. Oxytocin signaling in the lateral septum prevents social fear during lactation. Curr Biol. 2018;28:1066-78 e1066.

10. Zoicas I, Slattery DA, Neumann ID. Brain oxytocin in social fear conditioning and its extinction: Involvement of the lateral septum. Neuropsychopharmacology. 2014;39:3027-35.

11. Sabihi S, Durosko NE, Dong SM, Leuner B. Oxytocin in the prelimbic medial prefrontal cortex reduces anxiety-like behavior in female and male rats. Psychoneuroendocrinology. 2014;45:31-42.

12. Yoshida M, Takayanagi Y, Inoue K, Kimura T, Young LJ, Onaka $\mathrm{T}$, et al. Evidence that oxytocin exerts anxiolytic effects via oxytocin receptor expressed in serotonergic neurons in mice. $\mathrm{J}$ Neurosci. 2009;29:2259-71.

13. Landgraf R, Neumann ID. Vasopressin and oxytocin release within the brain: a dynamic concept of multiple and variable modes of neuropeptide communication. Front Neuroendocrinol. 2004;25:150-76.

14. Neumann ID. Stimuli and consequences of dendritic release of oxytocin within the brain. Biochem Soc Trans. 2007;35:1252-7.

15. Waldherr M, Neumann ID. Centrally released oxytocin mediates mating-induced anxiolysis in male rats. Proc Natl Acad Sci USA. 2007;104:16681-4.

16. Bosch OJ, Meddle SL, Beiderbeck DI, Douglas AJ, Neumann ID. Brain oxytocin correlates with maternal aggression: link to anxiety. J Neurosci. 2005;25:6807-15.

17. Torner L, Plotsky PM, Neumann ID, de Jong TR. Forced swimming-induced oxytocin release into blood and brain: effects of adrenalectomy and corticosterone treatment. Psychoneuroendocrinology. 2016;77:165-74.

18. Neumann ID, Wigger A, Torner L, Holsboer F, Landgraf R. Brain oxytocin inhibits basal and stress-induced activity of the hypothalamo-pituitary-adrenal axis in male and female rats: partial action within the paraventricular nucleus. J Neuroendocrinol. 2000;12:235-43.

19. Busnelli M, Chini B. Molecular basis of oxytocin receptor signalling in the brain: what we know and what we need to know. Curr Top Behav Neurosci. 2018;35:3-29.

20. Martinetz S, Meinung CP, Jurek B, von Schack D, van den Burg $\mathrm{EH}$, Slattery DA, et al. De novo protein synthesis mediated by the eukaryotic elongation factor 2 is required for the anxiolytic effect of oxytocin. Biol Psychiatry. 2019;85:802-11.

21. van den Burg EH, Stindl J, Grund T, Neumann ID, Strauss O. Oxytocin stimulates extracellular $\mathrm{Ca}^{2+}$ influx through TRPV2 channels in hypothalamic neurons to exert its anxiolytic effects. Neuropsychopharmacology. 2015;40:2938-47.

22. Jurek B, Slattery DA, Hiraoka Y, Liu Y, Nishimori K, Aguilera G, et al. Oxytocin regulates stress-induced $\mathrm{Crf}$ gene transcription through CREB-regulated transcription coactivator 3. J Neurosci. 2015;35:12248-60.

23. Smith AS, Tabbaa M, Lei K, Eastham P, Butler MJ, Linton L, et al. Local oxytocin tempers anxiety by activating GABAA receptors in the hypothalamic paraventricular nucleus. Psychoneuroendocrinology. 2016;63:50-58.

24. Deussing JM, Chen A. The corticotropin-releasing factor family: physiology of the stress response. Physiol Rev. 2018;98:2225-86.

25. Bale TL, Contarino A, Smith GW, Chan R, Gold LH, Sawchenko $\mathrm{PE}$, et al. Mice deficient for corticotropin-releasing hormone receptor-2 display anxiety-like behaviour and are hypersensitive to stress. Nat Genet. 2000;24:410-4.

26. Dabrowska J, Hazra R, Ahern TH, Guo JD, McDonald AJ, Mascagni F, et al. Neuroanatomical evidence for reciprocal regulation of the corticotrophin-releasing factor and oxytocin systems in the hypothalamus and the bed nucleus of the stria terminalis of the rat: implications for balancing stress and affect. Psychoneuroendocrinology. 2011;36:1312-26.

27. Janecek M, Dabrowska J. Oxytocin facilitates adaptive fear and attenuates anxiety responses in animal models and human studiespotential interaction with the corticotropin-releasing factor (CRF) system in the bed nucleus of the stria terminalis (BNST). Cell Tissue Res. 2019;375:143-72.

28. Grinevich V, Neumann ID. Brain oxytocin: how puzzle stones from animal studies translate into psychiatry. Mol Psychiatry. 2021;26:265-279.

29. Meyer-Lindenberg A, Domes G, Kirsch P, Heinrichs M. Oxytocin and vasopressin in the human brain: social neuropeptides for translational medicine. Nat Rev Neurosci. 2011;12:524-38.

30. Lee MR, Shnitko TA, Blue SW, Kaucher AV, Winchell AJ, Erikson DW, et al. Labeled oxytocin administered via the intranasal route reaches the brain in rhesus macaques. Nat Commun. 2020;11:2783.

31. Quintana DS, Alvares GA, Hickie IB, Guastella AJ. Do delivery routes of intranasally administered oxytocin account for observed effects on social cognition and behavior? A two-level model. Neurosci Biobehav Rev. 2015;49:182-92.

32. Verhees M, Houben J, Ceulemans E, Bakermans-Kranenburg MJ, van IMH, Bosmans G. No side-effects of single intranasal oxytocin administration in middle childhood. Psychopharmacology. 2018;235:2471-7.

33. Peters S, Slattery DA, Uschold-Schmidt N, Reber SO, Neumann ID. Dose-dependent effects of chronic central infusion of oxytocin on anxiety, oxytocin receptor binding and stressrelated parameters in mice. Psychoneuroendocrinology. 2014;42:225-36.

34. Guzman YF, Tronson NC, Jovasevic V, Sato K, Guedea AL, Mizukami H, et al. Fear-enhancing effects of septal oxytocin receptors. Nat Neurosci. 2013;16:1185-7.

35. Huang H, Michetti C, Busnelli M, Manago F, Sannino S, Scheggia $\mathrm{D}$, et al. Chronic and acute intranasal oxytocin produce divergent social effects in mice. Neuropsychopharmacology. 2014;39:1102-14.

36. Bales KL, Perkeybile AM, Conley OG, Lee MH, Guoynes CD, Downing GM, et al. Chronic intranasal oxytocin causes long-term impairments in partner preference formation in male prairie voles. Biol Psychiatry. 2013;74:180-8. 
37. Pagani M, De Felice A, Montani C, Galbusera A, Papaleo F, Gozzi A. Acute and repeated intranasal oxytocin differentially modulate brain-wide functional connectivity. Neuroscience. 2020;445:83-94.

38. Slattery DA, Neumann ID. Chronic icv oxytocin attenuates the pathological high anxiety state of selectively bred Wistar rats. Neuropharmacology. 2010;58:56-61.

39. Bosch OJ, Neumann ID. Brain vasopressin is an important regulator of maternal behavior independent of dams' trait anxiety. Proc Natl Acad Sci USA. 2008;105:17139-44.

40. Neumann ID, Slattery DA. Oxytocin in general anxiety and social fear: a translational approach. Biol Psychiatry. 2016;79:213-21.

41. Jurek B, Meyer M. Anxiolytic and anxiogenic? How the transcription factor MEF2 might explain the manifold behavioral effects of oxytocin. Front Endocrinol. 2020;11:186.

42. Winter J, Jurek B. The interplay between oxytocin and the CRF system: regulation of the stress response. Cell Tissue Res. 2019;375:85-91.

43. Tachibana M, Kagitani-Shimono K, Mohri I, Yamamoto T, Sanefuji W, Nakamura A, et al. Long-term administration of intranasal oxytocin is a safe and promising therapy for early adolescent boys with autism spectrum disorders. J Child Adolesc Psychopharmacol. 2013;23:123-7.

44. MacDonald E, Dadds MR, Brennan JL, Williams K, Levy F, Cauchi AJ. A review of safety, side-effects and subjective reactions to intranasal oxytocin in human research. Psychoneuroendocrinology. 2011;36:1114-26.

45. Meyer M, Berger I, Winter J, Jurek B. Oxytocin alters the morphology of hypothalamic neurons via the transcription factor myocyte enhancer factor 2A (MEF-2A). Mol Cell Endocrinol. 2018;477:156-62.

46. Flavell SW, Cowan CW, Kim TK, Greer PL, Lin Y, Paradis S, et al. Activity-dependent regulation of MEF2 transcription factors suppresses excitatory synapse number. Science. 2006;311:1008-12.

47. Morrow EM, Yoo SY, Flavell SW, Kim TK, Lin Y, Hill RS, et al. Identifying autism loci and genes by tracing recent shared ancestry. Science. 2008;321:218-23.

48. Li H, Radford JC, Ragusa MJ, Shea KL, McKercher SR, Zaremba JD, et al. Transcription factor MEF2C influences neural stem/ progenitor cell differentiation and maturation in vivo. Proc Natl Acad Sci USA. 2008;105:9397-402.

49. Hurlemann R. Oxytocin-augmented psychotherapy: Beware of context. Neuropsychopharmacology. 2017;42:377.

50. Spengler FB, Schultz J, Scheele D, Essel M, Maier W, Heinrichs $\mathrm{M}$, et al. Kinetics and dose dependency of intranasal oxytocin effects on amygdala reactivity. Biol Psychiatry. 2017;82:885-94.

51. Grillon C, Krimsky M, Charney DR, Vytal K, Ernst M, Cornwell B. Oxytocin increases anxiety to unpredictable threat. Mol Psychiatry. 2013;18:958-60.

52. Kilkenny C, Browne WJ, Cuthill IC, Emerson M, Altman DG. Improving bioscience research reporting: the ARRIVE guidelines for reporting animal research. J Pharm Pharmacother. 2010;1:94-99.

53. Neumann ID, Torner L, Wigger A. Brain oxytocin: differential inhibition of neuroendocrine stress responses and anxiety-related behaviour in virgin, pregnant and lactating rats. Neuroscience. 2000;95:567-75.

54. Lukas M, Toth I, Reber SO, Slattery DA, Veenema AH, Neumann ID. The neuropeptide oxytocin facilitates pro-social behavior and prevents social avoidance in rats and mice. Neuropsychopharmacology. 2011;36:2159-68.

55. Fuchsl AM, Uschold-Schmidt N, Reber SO. Chronic psychosocial stress in male mice causes an up-regulation of scavenger receptor class $B$ type 1 protein in the adrenal glands. Stress. 2013;16:461-8
56. Mugele K, Kugler H, Spiess J. Immortalization of a fetal rat brain cell line that expresses corticotropin-releasing factor mRNA. DNA Cell Biol. 1993;12:119-26.

57. Chen AM, Perrin MH, Digruccio MR, Vaughan JM, Brar BK, Arias $\mathrm{CM}$, et al. A soluble mouse brain splice variant of type 2alpha corticotropin-releasing factor (CRF) receptor binds ligands and modulates their activity. Proc Natl Acad Sci USA. 2005;102:2620-5.

58. Devost D, Wrzal P, Zingg HH. Oxytocin receptor signalling. Prog Brain Res. 2008;170:167-76.

59. Li K, Nakajima M, Ibanez-Tallon I, Heintz N. A cortical circuit for sexually dimorphic oxytocin-dependent anxiety behaviors. Cell. 2016;167:60-72 e11.

60. Asok A, Draper A, Hoffman AF, Schulkin J, Lupica CR, Rosen JB. Optogenetic silencing of a corticotropin-releasing factor pathway from the central amygdala to the bed nucleus of the stria terminalis disrupts sustained fear. Mol Psychiatry. 2018;23:914-22.

61. Bale TL, Picetti R, Contarino A, Koob GF, Vale WW, Lee KF. Mice deficient for both corticotropin-releasing factor receptor 1 (CRFR1) and CRFR2 have an impaired stress response and display sexually dichotomous anxiety-like behavior. J Neurosci. 2002;22:193-9.

62. Radulovic J, Ruhmann A, Liepold T, Spiess J. Modulation of learning and anxiety by corticotropin-releasing factor (CRF) and stress: Differential roles of CRF receptors 1 and 2. J Neurosci. 1999;19:5016-25.

63. Migawa MT, Shen W, Wan WB, Vasquez G, Oestergaard ME, Low A, et al. Site-specific replacement of phosphorothioate with alkyl phosphonate linkages enhances the therapeutic profile of gapmer ASOs by modulating interactions with cellular proteins. Nucleic Acids Res. 2019;47:5465-79.

64. Andari E, Hurlemann R, Young LJ. A precision medicine approach to oxytocin trials. Curr Top Behav Neurosci. 2018:35:559-90.

65. Lovenberg TW, Chalmers DT, Liu C, De Souza EB. CRF2 alpha and CRF2 beta receptor mRNAs are differentially distributed between the rat central nervous system and peripheral tissues. Endocrinology. 1995; 136:4139-42.

66. Van Pett K, Viau V, Bittencourt JC, Chan RK, Li HY, Arias C, et al. Distribution of mRNAs encoding CRF receptors in brain and pituitary of rat and mouse. J Comp Neurol. 2000;428:191-212.

67. Evans RT, Seasholtz AF. Soluble corticotropin-releasing hormone receptor $2 \alpha$ splice variant is efficiently translated but not trafficked for secretion. Endocrinology. 2009;150:4191-202.

68. Markovic D, Grammatopoulos DK. Focus on the splicing of secretin GPCRs transmembrane-domain 7. Trends Biochem Sci. 2009;34:443-52.

69. Proudfoot NJ, Furger A, Dye MJ. Integrating mRNA processing with transcription. Cell. 2002;108:501-12.

70. Zhang Z, Cao M, Chang CW, Wang C, Shi X, Zhan X, et al. Autism-associated chromatin regulator $\mathrm{Brg} 1 / \mathrm{SmarcA} 4$ is required for synapse development and myocyte enhancer factor 2-mediated synapse remodeling. Mol Cell Biol. 2016;36:70-83.

71. Slater PG, Cerda CA, Pereira LA, Andrés ME, Gysling K. CRF binding protein facilitates the presence of CRF type $2 \alpha$ receptor on the cell surface. Proc Natl Acad Sci USA. 2016;113:4075-80.

72. Wood SK, Zhang XY, Reyes BA, Lee CS, Van Bockstaele EJ, Valentino RJ. Cellular adaptations of dorsal raphe serotonin neurons associated with the development of active coping in response to social stress. Biol Psychiatry. 2013;73:1087-94.

73. Waselus M, Nazzaro C, Valentino RJ, Van Bockstaele EJ. Stressinduced redistribution of corticotropin-releasing factor receptor subtypes in the dorsal raphe nucleus. Biol Psychiatry. 2009;66:76-83. 